\title{
Within-milking variation in milk composition and fatty acid profile of Holstein dairy cows
}

\author{
D. E. Rico, ${ }^{*}$ E. R. Marshall, ${ }^{* 1}$ J. Choi, $\dagger^{2}$ K. E. Kaylegian, † C. D. Dechow, ${ }^{*}$ and K. J. Harvatine ${ }^{* 3}$ \\ ${ }^{*}$ Department of Dairy and Animal Science, and \\ †Department of Food Science, Penn State University, University Park 16802
}

\begin{abstract}
Changes in milk composition during a milking are well characterized, but variation in milk fatty acid (FA) profile is not well described and may affect the accuracy of in-line milk composition analyzers and could potentially be used for selective segregation of milk. Within-milking samples were collected from 8 multiparous high-producing Holstein cows $(54.86 \pm 6.8 \mathrm{~kg}$ of milk/d; mean \pm standard deviation). A milk-sampling device was designed to allow collection of multiple samples during a milking without loss of vacuum or interruption of milk subsampling. Milk was collected during consecutive morning and afternoon milkings (12-h intervals) and was replicated 1 wk later. Each sample represented approximately $20 \%$ of the milking and was analyzed for fat, true protein, and lactose concentration and FA profile. Milk fat concentration markedly increased over the course of milk let down (4.4 and 4.2 percentage units at the a.m. and p.m. milking, respectively), whereas milk fat globule size did not change. Milk protein and lactose concentration decreased slightly during milking. Modest changes in milk FA profile were also observed, as milk de novo and 16-C FA concentrations increased approximately 10 and $8 \%$, respectively, whereas the concentration of preformed FA decreased about $7 \%$ during the milking. In agreement, mean milk FA chain length and unsaturation modestly decreased during milking (0.59 and $0.014 \mathrm{U}$, respectively). The observed changes in milk fat concentration during a milking are consistent with previous reports and reflect the dynamic nature of milk fat secretion from the mammary gland. Changes in milk FA profile are not expected to practically affect the accuracy of spectroscopy methods for determina-
\end{abstract}

\footnotetext{
Received November 18, 2013.

Accepted March 22, 2014.

${ }^{1}$ Current address: Virginia-Maryland Regional College of Veterinary Medicine, Blacksburg, VA.

${ }^{2}$ Current address: National Institute of Animal Science, Rural Development Administration, Suwon, Gyeonggi, 441706, Republic of Korea.

${ }^{3}$ Corresponding author: kjh182@psu.edu
}

tion of milk fat concentration. Furthermore, the small variation in FA profile during a milking limits the use of within-milking milk segregation to tailor milk FA profile.

Key words: milk composition, milk letdown, in-line milk meter

\section{INTRODUCTION}

Milk composition and FA profile can be affected by several factors, such as nutritional practices, season, genetics, and stage of lactation [see reviews by DePeters and Cant (1992), Fox and McSweeney (1998), and Bauman and Griinari (2003)]. Precision management of dairy cows may be aided by determination of milk composition in every cow at each milking (Maltz et al., 2013) and in-line analysis systems have been developed based on near-infrared (NIR) spectral analysis [e.g., AfiLab (SAE Afikim, Kibbutz Afikim, Israel); Melfsen et al., 2012a; Leitner et al., 2013]. Additionally, in-line analysis systems have been used to segregate milk within a milking based on predicted cheese yield (Leitner et al., 2013) and a similar approach could be used if sufficient within-milking variation in FA profile existed.

Changes in milk composition during a milking are well recognized. Experiments spanning almost $75 \mathrm{yr}$ report a pronounced increase in milk fat concentration and a small decrease in nonfat milk solids during a milking (Bartlett, 1934; Whittlestone, 1953; Nielsen et al., 2005). The exact reason for the variation in milk fat concentration during a milking is not clear, but several theories have been proposed over the years, including the progressive filtration of milk fat globule (MFG) clusters through the mammary ducts [see review by Whittlestone (1953)], mechanical shearing of alveolar contractions, and decreasing adsorption of MFG to the alveolar wall during milking [see review by Atwood and Hartmann (1992)]. Additionally, a circadian rhythm of milk FA concentration and profile has been reported and may affect milk fat concentration and profile of cistern and alveolar milk (Daly et al., 1993; RottmanGredell et al., 2014).

Changes in milk FA profile during a milking have not been investigated, to our knowledge. The accuracy of 
laboratory-based mid-infrared (MIR) methods is affected by mean FA chain length or degree of unsaturation (Kaylegian et al., 2009b) and NIR spectra are also modified by FA profile, as they are able to distinguish some FA classes (Villar et al., 2012). The objective of the current experiment was to characterize the changes in milk FA profile during a milking. We hypothesized that the concentration of milk fat would increase during the course of each milking, but milk FA profile would be more modestly affected.

\section{MATERIALS AND METHODS}

\section{Animals and Experimental Design}

All experimental procedures were approved by the Pennsylvania State University Institutional Animal Care and Use Committee (University Park). Eight high-producing multiparous Holstein cows (54.9 \pm 6.8 $\mathrm{kg}$ of milk/d; $3.3 \pm 1.4$ lactations; $72.2 \pm 14.2$ DIM; mean $\pm \mathrm{SD}$ ) from the Pennsylvania State University Dairy Production Research and Teaching Center were used in a repeated design to study the variation in milk composition within a milking. All cows were housed in individual tie-stalls, milked twice per day (0500 and $1700 \mathrm{~h}$ ), and fed the same ration once per day in the morning. The ration was balanced to contain $31.5 \%$ NDF, $17.4 \% \mathrm{CP}$, and $5.2 \%$ ether extract.

\section{Milk Sampling and Analysis}

Milk sampling was conducted for each cow during consecutive evening and morning milkings, and repeated 1 wk later. Milk yield was determined by an integrated milk meter (Afimilk, SAE Afikim). A milk sampling device was designed to allow for collection of individual fractions during a milking while maintaining continuous sampling without loss of vacuum (Figure 1 ). Briefly, a $2.54-\mathrm{cm}$ polyvinyl chloride valve was connected between the parlor sample bottle (Afimilk, SAE Afikim) and a 300-mL screw-top polycarbonate bottle. The valve was opened at the end of each sampling interval and immediately closed after the top sample bottle was emptied. Milk was then subsampled from the bottom sample bottle. Milk was collected, representing 5 almost equal intervals from each cow, by sampling when milk yield reached $20,40,60,80$, and $100 \%$ of the mean milk production from the previous 7 corresponding milkings (a.m. or p.m.). A sixth sample was collected if total milk yield exceeded the expected value by more than $5 \%$. Each sample, representing approximately $20 \%$ of the milking, was subdivided into 2 aliquots. One aliquot was stored at $4^{\circ} \mathrm{C}$ with preservative (Bronolab-WII; Advanced Instruments Inc., Norwood,
MA) until analyzed for fat (Filter B), protein, and lactose by MIR [Fossomatic 4000 MilkoScan [Foss Electric A/S, Hillerød, Denmark); AOAC International, 2000 (method 972.160); Dairy One Inc., State College, PA]. The instrument was calibrated following regulatory procedures outlined for producer payment sample testing. The calibration set consisted of 12 known component samples tested by reference wet chemistry within the range of 2.5 to $5.25 \%$ butterfat. The second aliquot was spun at $1,500 \times g$ for $20 \mathrm{~min}$ at $4^{\circ} \mathrm{C}$ and the resulting fat cake was stored at $-20^{\circ} \mathrm{C}$ without preservative for FA analysis. Lipid was extraction according to Feng et al. (2004), with slight modification. Briefly, frozen fat cake was incubated $20 \mathrm{~min}$ at $45^{\circ} \mathrm{C}$ and then centrifuged at 20,000 $\times g$ for $30 \mathrm{~min}$ at ambient temperature in a sealed microcentrifuge (5424; Eppendorf AG, Hamburg, Germany). A subsample of the resulting oil (40 $\mathrm{mg}$ ) was solubilized in $2 \mathrm{~mL}$ of hexane plus butylated hydroxytoluene (BHT; $100 \mathrm{mg} / \mathrm{L}$ ), transmethylated in the presence of sodium methoxide, and FAME quantified by gas-liquid chromatography using a fused-silica capillary column and a flame ionization detector, as previously described by Rico and Harvatine (2013).

\section{Mean FA Chain Length and Unsaturation and Fat Melting Point}

Mean FA chain length and unsaturation were calculated according to Kaylegian et al. (2009a). Briefly, the molar concentration of each FA was weighted by number of carbons or double bonds and averaged by sample. Milk fat melting temperature was calculated based on the melting temperature of individual FA and their relative proportion similar to Toral et al. (2013).

\section{MFG Size}

Milk fat globule size distribution was determined on a subset of 5 cows during 1 morning milking. Samples were immediately stored at $4^{\circ} \mathrm{C}$ following collection and processed within $5 \mathrm{~h}$. Samples were warmed at $30^{\circ} \mathrm{C}$ for $20 \mathrm{~min}$ and then for an additional 60 min following a 1:1 dilution with 5\% SDS to allow for dissociation of flocculated fat globules. Samples were then analyzed by laser light scattering (2 measurements per sample; Horiba LA-920; Horiba Instruments Inc., Irvine, CA) as described by Tangsuphoom and Coupland (2009). Median diameter was calculated by instrument software and volume surface average and volume mean diameter were calculated as described by Michalski et al. (2006). Additionally, the distributions of MFG were deconvoluted into multiple normal distributions using WinSAAM software (version 3.0.8; New Bolton Center, Biostatistics Unit, University of Pennsylvania, Kennett 


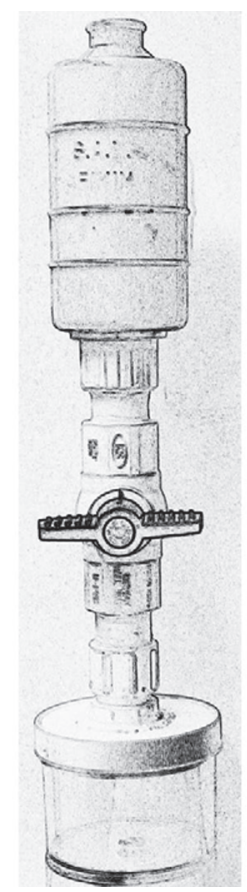

Figure 1. Milk sampling device used for collection of individual milking fractions during a milking without disruption of vacuum or sample loss. The middle valve was opened at the end of each sampling interval and immediately closed after the top sample bottle was emptied. Milk was then subsampled from the bottom sample bottle.

Square) as described by Boston et al. (2008). Data best fit a model with 2 Gaussian distributions and allowed determination of mean globule size, spread (mean distribution width), and area under the curve (\% of total) for each distribution.

\section{Statistical Analysis}

Data were analyzed by random regression using PROC MIXED of SAS (version 9.3; SAS Institute Inc., Cary, NC) with the repeated statement. Milking fraction (MF) was a continuous variable calculated as the midpoint of each sampling interval as a fraction of the actual milk yield. The model was

$$
\begin{gathered}
\mathrm{Y}_{\mathrm{ijkl}}=\mu+\mathrm{C}_{\mathrm{i}}+\mathrm{W}_{\mathrm{j}}+\mathrm{M}_{\mathrm{k}}+\mathrm{MF}_{\mathrm{l}}+\mathrm{MF}_{\mathrm{l}}^{2} \\
+\mathrm{M}_{\mathrm{k}} \times \mathrm{MF}_{\mathrm{l}}+\mathrm{M}_{\mathrm{k}} \times \mathrm{MF}_{\mathrm{l}}^{2}+\mathrm{e}_{\mathrm{ijkl}},
\end{gathered}
$$

where $Y_{i j k l}$ is the variable of interest; $\mu$ is the overall mean; $\mathrm{C}_{\mathrm{i}}$ is the random effect of cow $(\mathrm{i}=1$ to 8$) ; \mathrm{W}_{\mathrm{j}}$ is the random effect of week ( $\mathrm{j}=1$ or 2$) ; \mathrm{M}_{\mathrm{k}}$ is the fixed effect of milking $\left(\mathrm{k}=\right.$ a.m. or p.m.); $\mathrm{MF}_{1}$ and $\mathrm{MF}_{1}^{2}$ are the fixed linear and quadratic effects of milking fraction, respectively; $\mathrm{M}_{\mathrm{k}} \times \mathrm{MF}_{1}$ is the interaction of milking and linear effect of milking fraction; $\mathrm{M}_{\mathrm{k}} \times \mathrm{MF}_{1}^{2}$ is the interaction of milking and the quadratic effect of milking fraction; and $\mathrm{e}_{\mathrm{ijkl}}$ is the residual error. The subject was cow and the model included a random intercept. Denominator degrees of freedom were calculated by the Satterthwaite procedure. Unstructured and autoregressive order 1 covariance structures were used based on model fit. Given that PROC MIXED does not yield coefficient of determination values in random regression, the coefficient of determination was calculated from the correlation between observed and model predicted values as a measure of model fit. Points outside of \pm 3 studentized residuals were considered outliers and removed from analysis, although few outliers were observed (typically less than 2 per response variable).

\section{RESULTS}

\section{Milk Composition and Cumulative Yield}

Interactions between milking time (a.m. and p.m.) and the linear and quadratic effects of milking fraction were detected for milk fat concentration and cumulative milk fat yield as a percentage of total milk fat yield (Table 1; Figures 2a and 3). Although milk fat concentration and cumulative yield increased quadratically by approximately 4 percentage units at both milkings, the linear rate was higher at the p.m. than the a.m. milking, whereas the quadratic rate was higher at the a.m. than at the p.m. milking. No interactions of milking fraction and milking time were detected for the concentration or cumulative yield as a percentage of total yield for milk protein or lactose $(P>0.2)$. The concentrations of milk fat and protein were both quadratically decreased over the course of milking, although the magnitude of the change was low (approximately 0.1 percentage unit; $P$ $<0.001$; Figures 2B and 2C). The cumulative yields of lactose and protein were also quadratically decreased over the course of milking, although the linear slope was near 100 and the quadratic effect was small $(P<$ 0.001 ; Figure 3). Only milk protein is shown in Figure 3 , as milk lactose was almost identical and was superimposed on milk protein when graphed together.

\section{Milk FA Profile}

No interactions of milking time and milking fraction were detected for the concentration of individual milk FA as a percentage of total FA, except for C14:0 (Table 2 ). De novo synthesized FA (sum of FA $<16 \mathrm{C}$ ) increased quadratically over the course of milking (approximately 3.0 percentage units, or 9.5\%; $P<0.01$; Figure $4 \mathrm{~A}$ ). Specifically, C4:0, C6:0, and C8:0 were unchanged, whereas C10:0 increased linearly and C12:0, C14:1, and C15:0 increased quadratically $(P<0.05)$, although the 
Table 1. Change in milk composition within a milking in dairy cows ${ }^{1}$

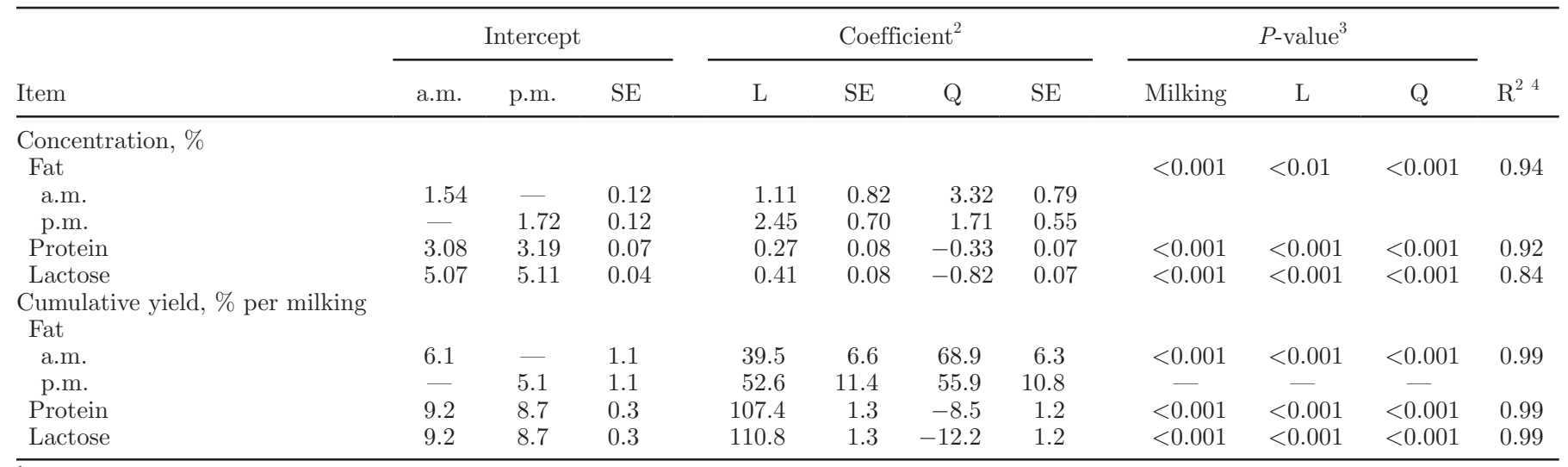

${ }^{1}$ Model: $\mathrm{Y}=$ milking time-specific intercept + linear effect of milking fraction $(\mathrm{L})+$ quadratic effect of milking fraction $(\mathrm{Q})$. The milking fraction ranged from the start of milking (0) to the end of milking (1). Intercepts for a.m. and p.m. milkings and the SE of the estimates are shown. ${ }^{2}$ Regression coefficient for milk component concentration and yield (\% or g) over the course of a milking and the SE of the estimate.

${ }^{3}$ Significance of milking (a.m. vs. p.m.), linear effect of milking fraction (L), and quadratic effect of milking fraction (Q). Interactions between the milking time-specific intercept and the linear and quadratic effects of milking fraction were observed for milk fat $(P=0.11$ and $P=0.04$, respectively), but not for protein and lactose concentrations $(P>0.2)$.

${ }^{4}$ The $\mathrm{R}^{2}$ values represent the association between the predicted versus observed values.

magnitude of the changes were only $5,10.2$, and $8.6 \%$ of the initial value. Additionally, C14:0 concentration increased during the course of milking; however, the linear rate was higher in the a.m. $(0.43$ and $-0.62 \%$ of FA/milking for a.m. and p.m., respectively) and the quadratic rate was lower in the a.m. $(-0.21$ and $0.91 \%$ of FA/milking for a.m. and p.m., respectively), resulting in less than a 3\% change in C14:0 over the milking. The sum of 16-C FA exhibited a quadratic increase (approximately 1.5 percentage units, or $6.9 \% ; P<$ 0.001; Figure 4B) and C16:0 and cis-9 C16:1 followed a similar pattern. Preformed FA (sum of FA >16 C) decreased quadratically during milking (approximately 2.5 percentage units, or $6.5 \%$; $P<0.001$; Figure $4 \mathrm{~B}$ ). In agreement, most individual preformed FA decreased or tended to decrease quadratically. Of specific interest, trans-10 C18:1 tended to decrease and trans-11 C18:1 decreased quadratically during milking $(P=0.09$ and $P<0.001$, respectively; 6.1 and $10.0 \%$ change over the milking). Additionally, C17:0 and cis-9,trans-11 CLA were not changed during milking, and trans-10,cis-12 CLA concentration remained below the level of detection across milking times and fractions.

Mean FA chain length tended to decrease and mean FA unsaturation decreased linearly during milking $(P=$ 0.06 and $P<0.01$, respectively; Table 2; Figure 5A and $5 \mathrm{~B}$, respectively), although the magnitude of change was low $(-0.059$ and $-0.014 \mathrm{U}$, respectively). Calculated milk fat melting point quadratically decreased during the a.m. milking and quadratically increased during the p.m. milking $(P<0.05)$, although the magnitude of the change was small $\left(<0.6^{\circ} \mathrm{C}\right)$

\section{MFG Size}

Median diameter, volume surface average, and volume mean diameter of MFG did not change during the course of milking and averaged $3.14 \pm 0.13,3.79$ \pm 0.11 , and $3.97 \pm 0.11$, respectively, at the start of the milking (mean $\pm \mathrm{SE}$; Table 3 ). No major differences were observed in the MFG distribution plots, as shown with the first and last fraction in Figure 6. The distribution was deconvoluted into 2 distributions. The mean globule sizes in each distribution were $3.2 \pm 0.08$ and $5.5 \pm 0.31 \mu \mathrm{m}$ (mean $\pm \mathrm{SE}$ ), and were not different between milking fractions 0.1 and 0.9 (Table 4). In addition, the area under the curve $(96.2 \pm 5.2$ and 10.1 \pm 3.0 , respectively) and the mean distribution spreads $(1.56 \pm 0.12$ and $0.64 \pm 0.24$, respectively) of the 2 distributions were not different between the first and last sample collected.

\section{DISCUSSION}

Milk yield of individual cows is commonly electronically recorded in modern milking systems and aids in nutrition and management decisions. However, the concentration of milk components, especially milk fat, is also important for identifying specific changes in energy balance, cow health, and metabolism. In-line milk analyzers have been developed to determine milk composition during a milking (Schmilovitch et al., 2007; Melfsen et al., 2012b). Variation in milk composition over the course of milking is a challenge that must be considered and has been previously studied in 

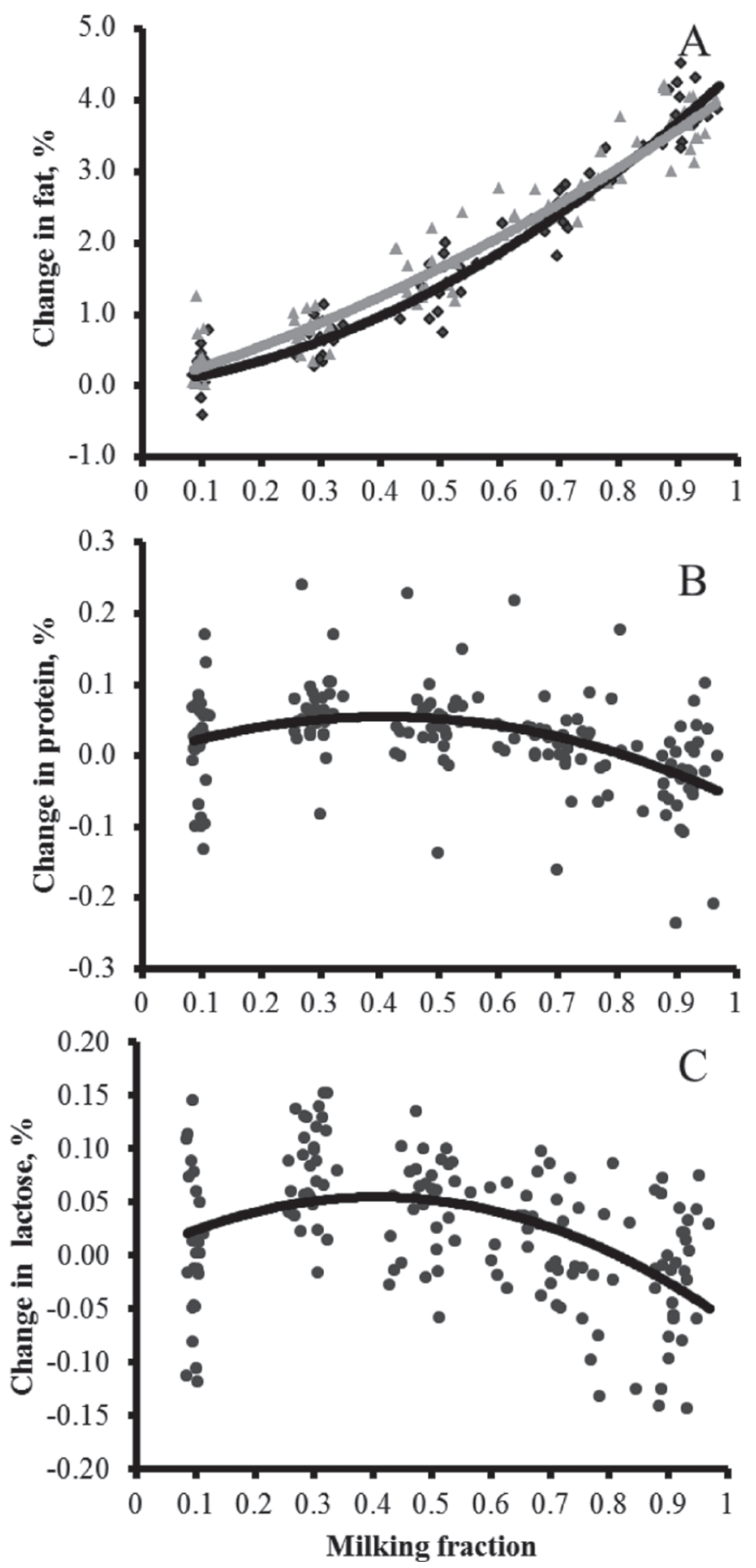

Figure 2. Change in milk fat (A), protein (B), and lactose (C) during the course of milking in dairy cows. The best-fit regression lines are plotted with a zero intercept for each component using the estimates reported in Table 1. A milking (morning vs. evening) by milking fraction interaction was observed for milk fat $(P=0.11)$; therefore, morning milking is shown in black and afternoon milking in shown in gray. The SE of the linear and quadratic estimates were 0.82 and 0.79 , and 0.70 and 0.55 for milk fat percentage at the a.m. and p.m. milkings, respectively; and 0.08 and 0.07 , and 0.08 and 0.07 for milk protein and lactose percentage, respectively. The $\mathrm{R}^{2}$ for the predicted versus observed values were $0.94,0.92$, and 0.84 for milk fat, protein, and lactose percentages, respectively. The residual of each observation is shown.

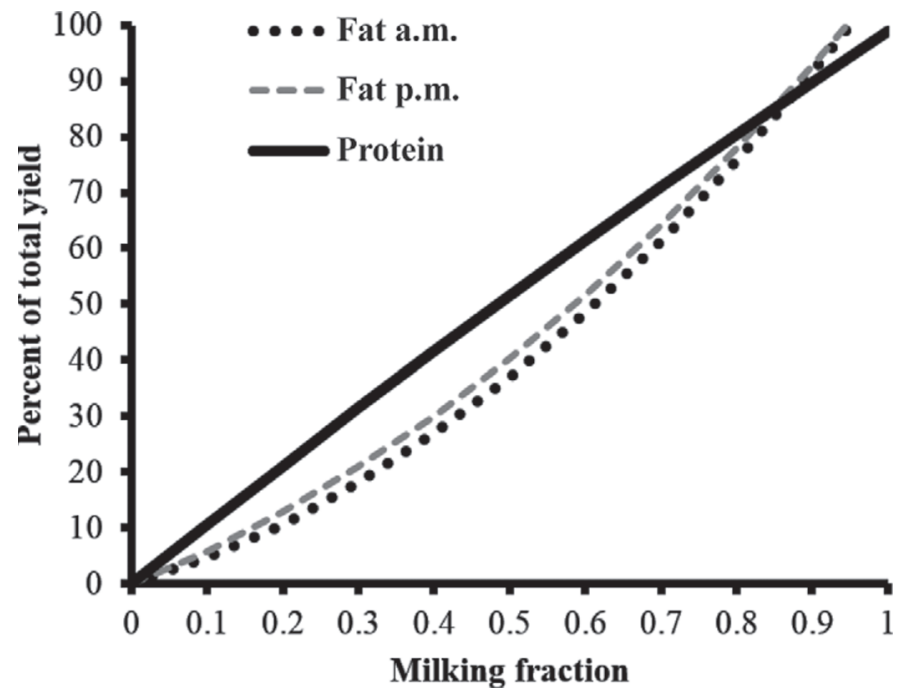

Figure 3. Cumulative yield of milk protein and fat over a milking as a percentage of total yield. The best-fit regression lines are plotted for each component using the estimates reported in Table 1. A milking (a.m. vs. p.m.) by milking fraction interaction was observed for milk fat $(P<0.05)$; therefore, a.m. milking is shown in black and p.m. milking is shown in gray. Milk lactose superimposes on milk protein yield and is not shown in the figure. The SE of the linear and quadratic estimates were 6.64 and 4.74 and 6.35 and 4.52 for milk fat percentage at the a.m. and p.m. milkings, respectively, and 1.30 and 1.24 for milk protein percentage. The $\mathrm{R}^{2}$ for the predicted versus observed was 0.99 for both milk fat and protein percentage.

different species by comparison of the composition of samples before and after milk letdown (Atwood and Hartmann, 1992; Daly et al., 1993) or by continuous analysis of samples during the milking process (Nielsen et al., 2005; Leitner et al., 2013). The sampling device used in the current experiment allowed for continuous collection during each milking across 5 almost-equal intervals, and random regression analysis characterized the changes during milking while accounting for cow and milking time effects.

Milk fat concentration has been reported to increase dramatically during milking in several species, including humans, sows, and cows (Atwood and Hartmann, 1992; Daly et al., 1993; Nielsen et al., 2005). Similarly, we observed a progressive increase in milk fat concentration of more than 4 percentage units. Nielsen et al. (2005) reported a similar increase of 5 percentage units in milk fat concentration during the morning milking in healthy cows when milked at 12 -h intervals, whereas milk fat increased only 3 percentage units when cows were milked at 6 -h intervals in the afternoon. It appears that the differences were due to milking intervals and not time of day, as only minor differences were observed between morning and evening milkings in the current experiment. Nielsen et al. (2005) speculated that the increased content of high-fat alveolar milk from an incomplete previous milking may be the reason why 
Table 2. Change in milk FA profile within a milking in dairy cows ${ }^{1}$

\begin{tabular}{|c|c|c|c|c|c|c|c|c|c|c|c|}
\hline Item & \multicolumn{3}{|c|}{ Intercept } & \multicolumn{4}{|c|}{ Coefficient $^{2}$} & \multicolumn{3}{|c|}{$P$-value ${ }^{3}$} & $\mathrm{R}^{24}$ \\
\hline \multicolumn{12}{|l|}{$\mathrm{FA}, \%$ of $\mathrm{FA}$} \\
\hline $\mathrm{C} 6: 0$ & 2.78 & 2.77 & 0.09 & 0.011 & 0.040 & - & - & $<0.001$ & 0.79 & - & 0.79 \\
\hline $\mathrm{C} 8: 0$ & 1.60 & 1.60 & 0.05 & 0.017 & 0.020 & - & - & $<0.001$ & 0.39 & - & 0.84 \\
\hline C10:0 & 3.80 & 3.74 & 0.11 & 0.113 & 0.057 & - & - & $<0.001$ & 0.04 & - & 0.81 \\
\hline a.m. & 11.43 & - & 0.19 & 0.425 & 0.517 & -0.21 & 0.497 & & & & \\
\hline p.m. & - & 11.41 & 0.19 & -0.617 & 0.356 & 0.91 & 0.345 & & & & \\
\hline C14:1 & 0.95 & 1.01 & 0.05 & -0.387 & 0.116 & 0.455 & 0.111 & $<0.001$ & $<0.01$ & $<0.001$ & 0.81 \\
\hline C15:0 & 1.03 & 1.01 & 0.07 & -0.191 & 0.098 & 0.289 & 0.094 & $<0.001$ & 0.05 & $<0.01$ & 0.88 \\
\hline C16:0 & 25.50 & 24.88 & 0.87 & -5.185 & 1.068 & 6.748 & 1.030 & $<0.001$ & $<0.001$ & $<0.001$ & 0.89 \\
\hline C16:1 & 1.23 & 1.27 & 0.08 & -0.569 & 0.114 & 0.701 & 0.111 & $<0.001$ & $<0.001$ & $<0.001$ & 0.88 \\
\hline C17:0 & 0.45 & 0.45 & 0.01 & -0.003 & 0.005 & - & - & $<0.001$ & 0.52 & - & 0.88 \\
\hline trans-10 C18:1 & 0.63 & 0.68 & 0.14 & 0.10 & 0.09 & -0.14 & 0.08 & $<0.001$ & 0.23 & 0.09 & 0.97 \\
\hline trans-11 C18:1 & 1.09 & 1.13 & 0.09 & 0.269 & 0.105 & -0.385 & 0.101 & $<0.001$ & 0.01 & $<0.001$ & 0.92 \\
\hline trans-12 C18:1 & 0.47 & 0.49 & 0.03 & 0.130 & 0.069 & -0.143 & 0.067 & $<0.001$ & 0.06 & 0.03 & 0.74 \\
\hline cis-9 C18:1 & 17.34 & 17.65 & 0.40 & 1.964 & 0.936 & -2.948 & 0.903 & $<0.001$ & 0.04 & $<0.01$ & 0.80 \\
\hline Linoleic acid & 3.85 & 4.08 & 0.18 & 0.608 & 0.272 & -0.724 & 0.261 & $<0.001$ & 0.03 & $<0.01$ & 0.86 \\
\hline $\mathrm{C} 20: 0$ & 0.14 & 0.13 & 0.01 & -0.008 & 0.005 & - & - & $<0.001$ & 0.09 & - & 0.55 \\
\hline$\alpha$-Linolenic acid & 0.61 & 0.64 & 0.03 & 0.113 & 0.043 & -0.137 & 0.041 & $<0.001$ & $<0.01$ & $<0.01$ & 0.87 \\
\hline cis-9, trans-11 CLA & 0.62 & 0.69 & 0.061 & -0.006 & 0.017 & - & - & $<0.001$ & 0.74 & - & 0.94 \\
\hline \multicolumn{12}{|l|}{ FA by source ${ }^{5} \%$ of FA } \\
\hline$\Sigma \mathrm{FA}<\mathrm{C} 16$ & 30.38 & 29.90 & 0.40 & -1.175 & 0.708 & 1.880 & 0.684 & $<0.001$ & 0.10 & 0.01 & 0.88 \\
\hline$\Sigma \mathrm{C} 16: 0+\mathrm{C} 16: 1$ & 26.46 & 25.86 & 0.89 & -5.164 & 1.067 & 6.850 & 1.030 & $<0.001$ & $<0.001$ & $<0.001$ & 0.92 \\
\hline$\Sigma \mathrm{FA}>\mathrm{C} 16$ & 35.84 & 36.41 & 0.59 & 5.607 & 1.678 & -8.025 & 1.619 & $<0.001$ & $<0.001$ & $<0.001$ & 0.67 \\
\hline \multicolumn{12}{|l|}{ FA characteristics } \\
\hline Mean chain length ${ }^{6}$ & 13.67 & 13.72 & 0.07 & -0.059 & 0.030 & - & - & $<0.001$ & 0.06 & - & 0.93 \\
\hline
\end{tabular}

${ }^{1}$ Model: $\mathrm{Y}=$ milking time-specific intercept + linear effect of milking fraction $(\mathrm{L})+$ quadratic effect of milking fraction $(\mathrm{Q})$. The milking fraction ranged from the start of milking (0) to the end of milking (1). Intercepts for a.m. and p.m. milkings and the SE of the estimates are shown. ${ }^{2}$ Regression coefficient of milk FA (\% of FA) over the course of a milking and SE of the estimate.

${ }^{3}$ Significance of milking (a.m. vs. p.m.), linear effect of milking fraction (L), and quadratic effect of milking fraction (Q). Interactions between the milking time-specific intercept and the linear and quadratic effects of milking fraction were observed only for C14:0 $(P<0.05)$.

${ }^{4}$ The $\mathrm{R}^{2}$ values represent the association between the predicted versus observed values.

${ }^{5} \mathrm{FA}<16 \mathrm{C}$ originate from mammary de novo synthesis, FA $>16 \mathrm{C}$ originate from plasma, and 16-C FA originate from both sources.

${ }^{6}$ Weighted mean carbon number.

${ }^{7}$ Weighted mean number of double bonds.

cows milked at shorter intervals would exhibit more moderate changes in milk fat during milking and higher average milk fat percentage. The change in milk fat during a milking has also been reported to be greater for low- than for high-producing cows [reviewed by Whittlestone (1953)], but milk yield in the current study $(55 \mathrm{~kg} / \mathrm{d})$ was approximately double that in the study of Nielsen et al. (2005), who observed a similar change in milk fat during milking when cows where milked at 12-h intervals. The observed decreased intercept of milk fat concentration for the morning milking in the current experiment is consistent with previous reports of lower milk fat concentration at the morning compared with evening milking (Quist et al., 2008; Forsbäck et al., 2010), but the difference is much smaller than the difference observed between 6- and 12-h intervals by Nielsen et al. (2005). Other factors, such as mammary gland health, can also affect the change in milk composition over the milking (Nielsen et al., 2005).

Based on the observed changes in milk fat, sampling at different times during milking can have a major effect on the concentration of milk fat. Thus, problems such as malfunctioning meters and insufficient sample agitation can potentially result in inaccurate determinations of milk fat. Importantly, many milk sample bottles have insufficient volume when sampling from very high-producing cows, which is a common issue experienced in some parlors. The modest decrease in milk 

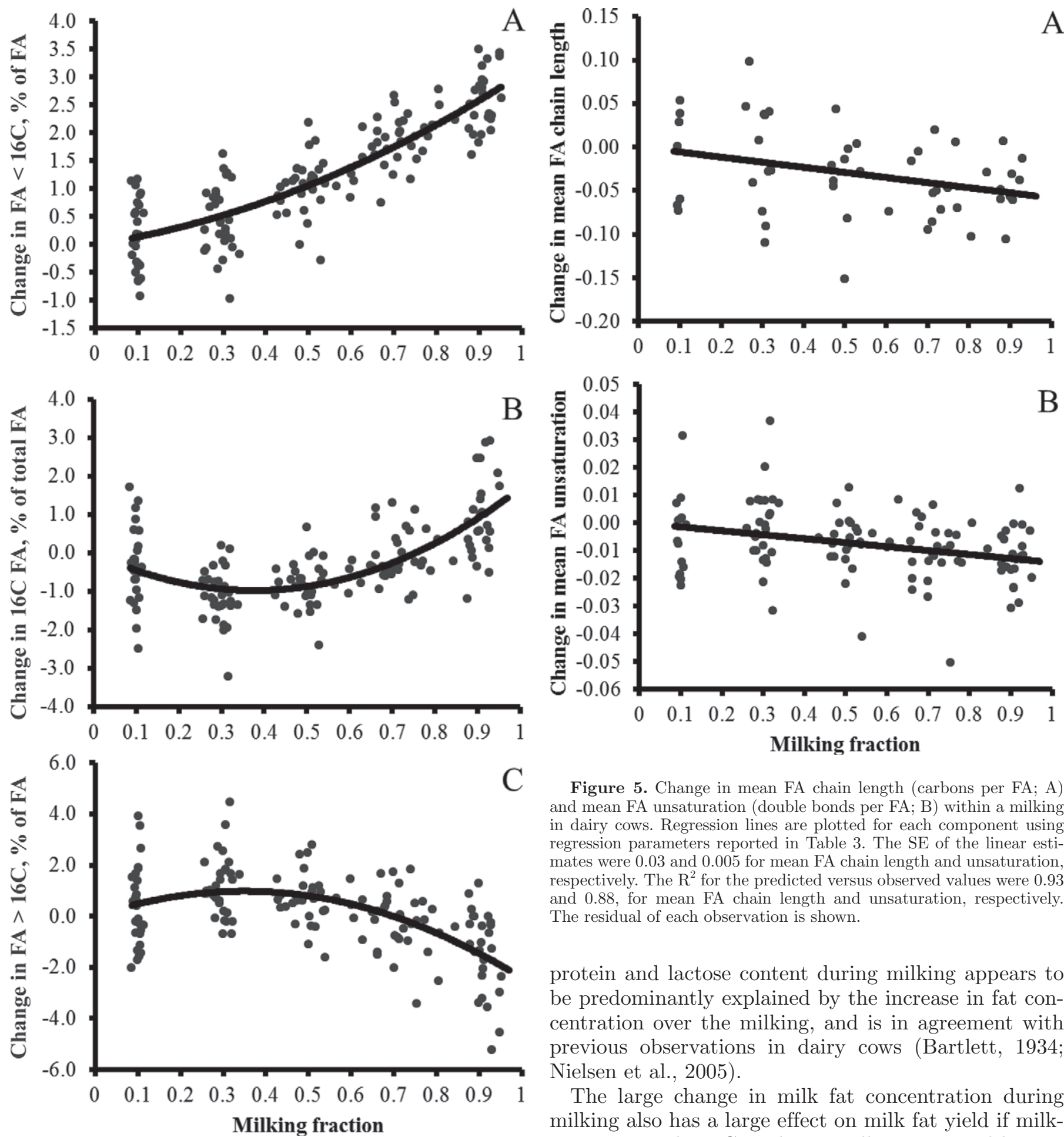

Figure 4. Change in milk fat concentration (\%) of de novo (A), 16-C (B), and preformed (C) FA within a milking in dairy cows. The best-fit regression lines are plotted with a zero intercept using the regression parameters reported in Table 2. The SE of the linear and quadratic estimates were 0.71 and $0.68,1.07$ and 1.03 , and 1.68 and 1.62 , for de novo, 16-C, and preformed FA, respectively. The $\mathrm{R}^{2}$ for the predicted versus observed values were $0.88,0.92$, and 0.67 for de novo, 16-C, and preformed FA, respectively. The residual of each observation is shown.

Figure 5. Change in mean FA chain length (carbons per FA; A) and mean FA unsaturation (double bonds per FA; B) within a milking in dairy cows. Regression lines are plotted for each component using regression parameters reported in Table 3 . The SE of the linear estimates were 0.03 and 0.005 for mean FA chain length and unsaturation, respectively. The $\mathrm{R}^{2}$ for the predicted versus observed values were 0.93 and 0.88 , for mean FA chain length and unsaturation, respectively. The residual of each observation is shown.

protein and lactose content during milking appears to be predominantly explained by the increase in fat concentration over the milking, and is in agreement with previous observations in dairy cows (Bartlett, 1934; Nielsen et al., 2005).

The large change in milk fat concentration during milking also has a large effect on milk fat yield if milking is incomplete. Cumulative milk protein and lactose yield linearly increase during milking, but milk fat yield increases quadratically (Figure 3). Complete milking is essential for maximal milk fat yield. For example, at the midpoint of milking, less than $36 \%$ of milk fat has been harvested.

The mechanism behind the increase in milk fat concentration during milking is not exactly known. Several 
RICO ET AL.

Table 3. Change in milk fat globule (MFG) size within a milking in dairy cows ${ }^{1}$

\begin{tabular}{|c|c|c|c|c|c|c|c|}
\hline \multirow[b]{2}{*}{ MFG diameter, ${ }^{2} \mu \mathrm{m}$} & \multicolumn{2}{|c|}{ Intercept } & \multicolumn{2}{|c|}{ Coefficient $^{3}$} & \multicolumn{2}{|c|}{$P$-value ${ }^{4}$} & \multirow[b]{2}{*}{$\mathrm{R}^{25}$} \\
\hline & a.m. & SE & $\mathrm{L}$ & SE & Intercept & $\mathrm{L}$ & \\
\hline$\overline{d_{\text {med }}}$ & 3.14 & 0.11 & -0.013 & 0.038 & $<0.001$ & 0.73 & 0.95 \\
\hline $\mathrm{d}_{32}$ & 3.79 & 0.13 & -0.019 & 0.055 & $<0.001$ & 0.73 & 0.92 \\
\hline$d_{43}$ & 3.97 & 0.13 & -0.025 & 0.059 & $<0.001$ & 0.67 & 0.92 \\
\hline
\end{tabular}

${ }^{1}$ Model: $\mathrm{Y}=$ intercept + linear effect of milking fraction $(\mathrm{L})$. The intercept for the a.m. milking and the SE of the estimate are shown.

${ }^{2}$ Milk fat globule diameter measures: $\mathrm{d}_{\text {med }}=$ diameter at middle of the population; $\mathrm{d}_{32}=$ volume surface average diameter; $\mathrm{d}_{43}=$ volume mean diameter.

${ }^{3}$ Regression coefficient of the MFG diameter $(\mu \mathrm{m})$ over the course of a milking and the SE of the estimate.

${ }^{4}$ Effect of the intercept and the linear effect of the milking fraction (L). No interactions between milking and linear and quadratic milking fraction were observed $(P>0.2)$.

${ }^{5}$ The $\mathrm{R}^{2}$ values represent the association between the predicted versus observed values.

theories have been proposed, including creaming of milk in the udder, delayed secretion from secretory cells, and adsorption to the epithelial lining, which were found to be inadequate based on innovative experiments, including milking goats on their back [reviewed by Whittlestone (1953)]. Whittlestone (1953) hypothesized that milk fat increases as a result of clustering of MFG in the alveolar lumen, which are partially filtered through the mammary ducts during ejection and are mostly forced out at the end of milking. A positive association exists between MFG size and daily fat yield in goats and cows (Wiking et al., 2004; Cebo et al., 2012), but median MFG size and the distribution of MFG populations by size did not change during milking in the current experiment, which is in agreement with previous reports in cows and humans (Whittlestone, 1953; Guinard-Flament et al., 2001; Mizuno et al., 2009). Atwood and Hartmann (1992) advanced the adsorption theory and proposed that a change in the shape of epithelial cells from squamous to columnar as the lumen empties would decrease the surface area for adsorption of fat globules to the alveolar lumen wall. This, coupled with the mechanical shearing forces of alveolar contraction, would result in most fat globules being released at the end of milking and may also explain the higher milk fat content (Atwood and Hartmann, 1992). The importance of mechanical shearing is supported by observation of electron micrographs that show that a significant amount of milk fat is fully surrounded by apical membrane, but has not fully separated from the epithelial cell (Heid and Keenan, 2005). Last, Mizuno et al. (2009) concluded that the higher fat concentration in hind- compared with foremilk was explained by increased number of MFG, rather than by an increase in their size, which is also in agreement with our observations.

To determine if a cow by milking fraction interaction existed, we modeled the data with cow and cow by milking fraction as fixed effects without repeated measures. Cow by milking fraction was not significant for milk lactose and protein concentration, but was significant for milk fat concentration. The sums of squares for cow by milking fraction were $17.6 \%$ of the total sums of squares. However, differences were due to the magnitude of the coefficients and did not change the overall interpretation of the change over the milking. Genetic and other differences contributing to a cow by milking fraction interaction may be investigated in the future with larger samples of cows across more diverse conditions (e.g., stage of lactation).

Milk fat globule size is normally analyzed as a single distribution, although multiple distributions are clearly present (Figure 6). Parametric deconvolution has been previously used to describe energy intake of human subjects by identification of distinct meal distributions

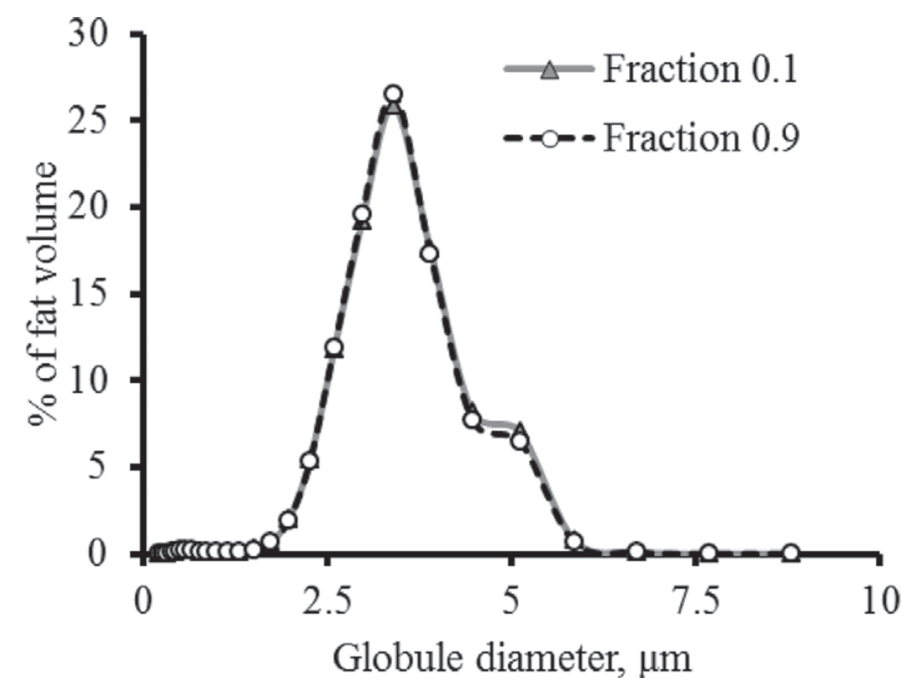

Figure 6. Average milk fat globule size distribution for the first and last fraction of milk collected. Other fractions not shown are also similar. 
Table 4. Deconvolution of milk fat globule size into 2 normal distributions

\begin{tabular}{|c|c|c|c|c|}
\hline \multirow[b]{2}{*}{ Item $^{1}$} & \multicolumn{2}{|c|}{ Milking fraction } & \multirow[b]{2}{*}{$\mathrm{SE}$} & \multirow[b]{2}{*}{$P$-value } \\
\hline & 0.1 & 0.9 & & \\
\hline \multicolumn{5}{|c|}{ First distribution } \\
\hline Mean, $\mu \mathrm{m}$ & 3.19 & 3.20 & 0.08 & 0.79 \\
\hline $\mathrm{AUC}_{\mathrm{DA}}, \%$ & 96.3 & 96.1 & 5.2 & 0.86 \\
\hline $\mathrm{DS}_{\mathrm{DA}}, \mu \mathrm{m}$ & 1.56 & 1.55 & 0.12 & 0.79 \\
\hline \multicolumn{5}{|c|}{ Second distribution } \\
\hline Mean, $\mu \mathrm{m}$ & 5.44 & 5.59 & 0.31 & 0.38 \\
\hline $\mathrm{AUC}_{\mathrm{DB}}, \%$ & 9.5 & 10.6 & 3.0 & 0.26 \\
\hline $\mathrm{DS}_{\mathrm{DB}}, \mu \mathrm{m}$ & 0.63 & 0.65 & 0.24 & 0.82 \\
\hline
\end{tabular}

${ }^{1}$ Parameters for the first and second normal distribution from deconvolution analysis, including mean $(\mu \mathrm{m})$ globule size of the 2 normal distributions fit by deconvolution; $\mathrm{AUC}_{\mathrm{DA}}$ and $\mathrm{AUC}_{\mathrm{DB}}$ (\% of fat volume) are the areas under the curve for the 2 normal distributions (A and $\mathrm{B}$, respectively); $\mathrm{DS}_{\mathrm{DA}}$ and $\mathrm{DS}_{\mathrm{DB}}$ are the widths of the distributions at half the peak height for distribution A and B, respectively.

during the day (Boston et al., 2008). Using this novel approach, we characterized the mean MFG size, area, and peak width of the 2 main populations of MFG in the first and last milk fraction. No differences existed in these parameters, in agreement with lack of differences in the conventional single-distribution MFG parameters. Only a subset of samples were analyzed for MFG size, but the lack of differences does not support further investigation and increased sample size appears unlikely to observe differences.

We observed a modest progressive increase in the proportion of de novo synthesized and 16-C FA $(\sim 10$ and $8 \%$, respectively) during milking, whereas the proportion of preformed FA decreased $(\sim 7 \%)$. To our knowledge, no previous reports exist on the variation in milk FA during the course of milking in dairy cows, and the mechanism behind these changes is not known. Differences in FA profiles between small and large MFG have been previously reported (Briard et al., 2003; Wiking et al., 2004; Couvreur et al., 2007); however, the lack of effect of milking fraction on MFG size in the present experiment suggests that FA profile changes are due to other factors yet to be elucidated. Last, FA melting temperature is important to the physical properties of milk fat. Although an interaction of milking time and milking fraction was observed, the change in calculated milk fat melting temperature was less than $0.6^{\circ} \mathrm{C}$ (Supplemental Figure S1, http://dx.doi. org/10.3168/jds.2013-7731), in agreement with rather small differences in melting temperature observed across different levels of milk fat yield and FA profile (Toral et al., 2013).

Changes in mean FA chain length and unsaturation alter the estimates of milk fat concentration by MIR when using traditional A and B wavelength filters. Kaylegian et al. (2009b) reported the differences between MIR predictions and reference chemistry as a function of mean FA chain length and unsaturation.
Based on these relationships, when comparing the first and last fraction in the current experiment, the difference between MIR predicted and reference chemistry would be 0.0033 and 0.0017 percentage units per $1 \%$ fat, based on mean chain length (by wavelength A) and unsaturation (by wavelength B), respectively. Thus, the reported milk fat concentration values in the current experiment had little bias due to FA profile. The effect of FA profile on in-line NIR analysis is not clear, but the modest change in FA profile over a milking limits the magnitude of the effect.

Within-milking segregation of milk based on clotting parameters for predicted cheese yield using an in-line sensor and 2 milk lines was demonstrated by Leitner et al., (2013). Currently, interest exists in milk as a functional food, as it contains specific unsaturated FA of interest to human health (e.g., n-3 FA, trans-11 C18:1, and cis-9, trans-11 CLA; Lock and Bauman, 2004), but development of enriched products has been challenging. Unfortunately, within-milking milk segregation based on FA profile appears to have limited potential to facilitate the enrichment of such FA because of the minor changes observed.

\section{CONCLUSIONS}

Milk fat is the most variable milk component within a milking and reflects the dynamic nature of milk fat secretion from the mammary gland. Milk FA profile is modestly, but predictably changed over the course of a milking. This magnitude of changes in milk FA profile is expected to have limited effect on in-line milk composition analysis, but also limits the potential to segregate milk within a milking based on FA profile. The mechanisms behind these changes are not clear, but highlight the importance of collection of representative samples during a milking. 


\section{ACKNOWLEDGMENTS}

The authors thank Yun Ying, Andrew Clarke, Katherine Cook, and Mutian Niu (Penn State University, University Park) for technical assistance. This research was supported in part by Agriculture and Food Research Initiative Competitive Grant no. 2010-6520620723 from the USDA National Institute of Food and Agriculture (Washington, DC) and an undergraduate research scholarship from Penn State University to E. R. Marshall.

\section{REFERENCES}

AOAC International. 2000. Official Methods of Analysis. 17th ed. AOAC International, Arlington, VA.

Atwood, C. S., and P. E. Hartmann. 1992. Collection of fore and hind milk from the sow and the changes in milk composition during suckling. J. Dairy Res. 59:287-298.

Bartlett, S. 1934. Variations in the solids-not-fat content of milk. I and II. J. Dairy Res. 5:113-123.

Bauman, D. E., and J. M. Griinari. 2003. Nutritional regulation of milk fat synthesis. Annu. Rev. Nutr. 23:203-227.

Boston, R. C., P. J. Moate, K. C. Allison, J. D. Lundgren, and A. J. Stunkard. 2008. Modeling circadian rhythms of food intake by means of parametric deconvolution: Results from studies of the night eating syndrome. Am. J. Clin. Nutr. 87:1672-1677.

Briard, V., N. Leconte, F. Michel, and M.-C. Michalski. 2003. The fatty acid composition of small and large naturally occurring milk fat globules. Eur. J. Lipid Sci. Technol. 105:677-682.

Cebo, C., C. Lopez, C. Henry, C. Beauvallet, O. Menard, C. Bevilacqua, F. Bouvier, H. Caillat, and P. Martin. 2012. Goat $\alpha_{\mathrm{s} 1}$-casein genotype affects milk fat globule physicochemical properties and the composition of the milk fat globule membrane. J. Dairy Sci. 95:6215-6229

Couvreur, S., C. Hurtaud, P. G. Marnet, P. Faverdin, and J. L. Peyraud. 2007. Composition of milk fat from cows selected for milk fat globule size and offered either fresh pasture or a corn silage-based diet. J. Dairy Sci. 90:392-403.

Daly, S. E. J., A. Di Rosso, R. A. Owens, and P. E. Hartmann. 1993. Degree of breast emptying explains changes in the fat content, but not fatty acid composition, of human milk. Exp. Physiol. 78:741-755.

DePeters, E. J., and J. P. Cant. 1992. Nutritional factors influencing the nitrogen composition of bovine milk: A review. J. Dairy Sci. 75:2043-2070.

Feng, S., A. L. Lock, and P. C. Garnsworthy. 2004. Technical note: A rapid lipid separation method for determining fatty acid composition of milk. J. Dairy Sci. 87:3785-3788.

Forsbäck, L., H. Lindmark-Månsson, A. Andrén, M. Åkerstedt, L. Andrée, and K. Svennersten-Sjaunja. 2010. Day-to-day variation in milk yield and milk composition at the udder-quarter level. J. Dairy Sci. 93:3569-3577.

Fox, P. F., and P. L. H. McSweeney. 1998. Milk lipids. Pages 68-71 in Dairy Chemistry and Biochemistry. Blackie Academic and Professional, London, U.K.

Guinard-Flament, J., M. C. Michalski, and H. Rulquin. 2001. Evolution of milk fat content and fat globule diameter according to milking time in dairy cows. Page 92 in Proc. 8th Conf. Rumin. Res., Paris, France.

Heid, H. W., and T. W. Keenan. 2005. Intracellular origin and secretion of milk fat globules. Eur. J. Cell Biol. 84:245-258.

Kaylegian, K. E., D. A. Dwyer, J. M. Lynch, D. E. Bauman, J. R. Fleming, and D. M. Barbano. 2009a. Impact of fatty acid composition on the accuracy of mid-infrared fat analysis of farm milks. J. Dairy Sci. 92:2502-2513.
Kaylegian, K. E., J. M. Lynch, J. R. Fleming, and D. M. Barbano. 2009b. Influence of fatty acid chain length and unsaturation on mid-infrared milk analysis. J. Dairy Sci. 92:2485-2501.

Leitner, G., U. Merin, S. Jacoby, D. Bezman, L. Lemberskiy-Kuzin, and G. Katz. 2013. Real-time evaluation of milk quality as reflected by clotting parameters of individual cow's milk during the milking session, between day-to-day and during lactation. Animal 7:1551-1558.

Lock, A. L., and D. E. Bauman. 2004. Modifying milk fat composition of dairy cows to enhance fatty acids beneficial to human health. Lipids 39:1197-1206.

Maltz, E., L. F. Barbosa, P. Bueno, L. Scagion, K. Kaniyamattam, L. F. Greco, A. De Vries, and J. E. P. Santos. 2013. Effect of feeding according to energy balance on performance, nutrient excretion, and feeding behavior of early lactation dairy cows. J. Dairy Sci. 96:5249-5266

Melfsen, A., E. Hartung, and A. Haeussermann. 2012a. Accuracy of in-line milk composition analysis with diffuse reflectance near-infrared spectroscopy. J. Dairy Sci. 95:6465-6476.

Melfsen, A., E. Hartung, and A. Haeussermann. 2012b. Accuracy of milk composition analysis with near infrared spectroscopy in diffuse reflection mode. Biosystems Eng. 112:210-217.

Michalski, M. C., N. Leconte, V. Briard-Bion, J. Fauquant, J. L. Maubois, and H. Goudédranche. 2006. Microfiltration of raw whole milk to select fractions with different fat globule size distributions: Process optimization and analysis. J. Dairy Sci. 89:3778-3790.

Mizuno, K., Y. Nishida, M. Taki, M. Murase, Y. Mukai, K. Itabashi, K. Debari, and A. Iiyama. 2009. Is increased fat content of hindmilk due to the size or the number of milk fat globules? Int Breastfeed. J. 4:7.

Nielsen, N. I., T. Larsen, M. Bjerring, and K. L. Ingvartsen. 2005 Quarter health, milking interval, and sampling time during milking affect the concentration of milk constituents. J. Dairy Sci $88: 3186-3200$

Quist, M. A., S. J. LeBlanc, K. J. Hand, D. Lazenby, F. Miglior, and D. F. Kelton. 2008. Milking-to-milking variability for milk yield, fat and protein percentage, and somatic cell count. J. Dairy Sci. 91:3412-3423.

Rico, D. E., and K. J. Harvatine. 2013. Induction of and recovery from milk fat depression occurs progressively in dairy cows switched between diets that differ in fiber and oil concentration. J. Dairy Sci. 96:6621-6630

Rottman-Gredell, L. W., Y. Ying, K. Zhou, P. A. Bartell, and K. H. Harvatine. 2014. The daily rhythm of milk synthesis is dependent on the timing of feed intake in dairy cows. Physiol. Rep. (Accepted).

Schmilovitch, Z., G. Katz, E. Maltz, M. I. Kutscher, M. Sarig, I. Halachmi, A. Hoffman, H. Egozi, and E. Unar. 2007. Spectroscopic fluid analyzer. S.A.E Afikim Computerized Dairy Management System, Agricultural Research Organization of The State of Israel Ministry of Agriculture, assignee. US Pat. No. 7,236,237 B2.

Tangsuphoom, N., and J. N. Coupland. 2009. Effect of surface-active stabilizers on the surface properties of coconut milk emulsions. Food Hydrocoll. 23:1801-1809.

Toral, P. G., L. Bernard, Y. Chilliard, and F. Glasser. 2013. Short communication: Diet-induced variations in milk fatty acid composition have minor effects on the estimated melting point of milk fat in cows, goats, and ewes: Insights from a meta-analysis. J. Dairy Sci. 96:1232-1236.

Villar, A., E. Gorritxategi, E. Aranzabe, S. Fernández, D. Otaduy, and L. A. Fernández. 2012. Low-cost visible-near infrared sensor for on-line monitoring of fat and fatty acids content during the manufacturing process of the milk. Food Chem. 135:2756-2760.

Whittlestone, W. G. 1953. 507. Variations in the fat content of milk throughout the milking process. J. Dairy Res. 20:146-153.

Wiking, L., J. Stagsted, L. Björck, and J. H. Nielsen. 2004. Milk fat globule size is affected by fat production in dairy cows. Int. Dairy J. 14:909-913. 